\title{
Cushing's Disease due to ACTH Secreting Pituitary Microadenoma: A Single Institutional Experience of Four Cases
}

\author{
Ashok Gandhi $^{1} \quad$ Mayur V. Barhate ${ }^{1} \quad$ Shashikant K. Jain ${ }^{1} \quad$ Sapna A. Gandhi \\ ${ }^{1}$ Department of Neurosurgery, Sawai Man Singh Medical College, \\ Jaipur, India \\ ${ }^{2}$ Department of Pathology, Sawai Man Singh Medical College, \\ Address for correspondence Mayur V. Barhate, MCh, Sawai Man Singh \\ Medical College, 102, Kiran Songir, Near DSK Vidyanagari, Pashan-Sus \\ Road, Baner, Pune 411045, India (e-mail: mayurvb2011@gmail.com).
} Jaipur, India

Indian J Neurosurg 2021;10:253-257.

\begin{abstract}
Keywords

- pituitary

- ACTH

- Cushing's disease

- microadenoma

ACTH secreting pituitary adenomas are rare occurrences in autoptical, surgical and neuroradiological series. We herewith describe a series of four patients of Cushing's disease due to ACTH secreting pituitary microadenoma. All patients presented with signs and symptoms of hypercortisolism. Hormonal testing and bilateral inferior petrosal sinus sampling were indicative of pituitary-dependent Cushing 's syndrome. Dynamic sellar MRI was suggestive of asymmetric pituitary, with suspect pituitary microadenoma in all cases. Three patients were operated for endoscopic endonasal transsphenoidal surgery, while one patient refused surgery and was managed with ketoconazole. During postoperative period, remission of hypercortisolism was ensured in two patients, while one patient continued to have raised levels of cortisol. One patient with raised levels of cortisol during postoperative period was prescribed Ketoconazole for 6 months. Histopathology confirmed the presence of pituitary adenoma. Adenoma displayed ACTH immunoreactivity. Our cases indicate that ACTH secreting pituitary microadenoma may occur in patients with Cushing's disease. Careful radiological, surgical and pathological examination is necessary to recognize this condition and avoid surgical failure.
\end{abstract}

\section{Introduction}

Cushing syndrome is a collection of signs and symptoms caused by excessive circulating glucocorticoid levels. It may occur by endogenous secretion or exogenous administration of glucocorticoids (iatrogenic Cushing syndrome). ACTHdependent Cushing syndrome is due to ACTH-secreting pituitary adenomas, ectopic ACTH-secreting tumors, and ectopic corticotropin-releasing hormone (CRH) syndrome. ${ }^{1}$ Cushing syndrome due to ACTH secreting pituitary adenoma is known as Cushing's disease. Differential diagnosis between Cushing disease and ectopic ACTH secreting tumors is difficult. There are many biochemical diagnostic tests and imaging studies such as magnetic resonance imaging (MRI), inferior petrosal sinus sampling, or scintigraphy

published online

September 25, 2020
DOI https://doi.org/

10.1055/s-0040-1713333

ISSN 2277-954X. available for the diagnosis of Cushing's disease. A dynamic pituitary MRI should be performed in all patients to diagnose ACTH-dependent Cushing disease. But in around 50\% cases, dynamic pituitary MRI fails to identify the exact tumor origin and site. ${ }^{2}$ Inferior petrosal sinus sampling (IPSS) confirm or exclude the diagnosis of Cushing's disease with 80 to $100 \%$ sensitivity and over $95 \%$ specificity. ${ }^{3}$ IPSS is considered the gold standard for identifying both the origin of tumors and the site of a pituitary adenoma. ${ }^{3}$ Baseline central-peripheral gradients have suboptimal accuracy, and stimulation with $\mathrm{CRH}$, possibly desmopressin, has to be performed. ${ }^{4}$ Majority of pituitary microadenoma are due to nonfunctioning adenoma, $\mathrm{GH}$ or prolactin secreting adenomas. ACTH secreting tumors are rare occurrences. 


\section{Case Series}

All patients included in the study presented with signs and symptoms of hypercortisolism, ( - Fig. 1) that is, weight gain with central fat distribution, amenorrhea in female patients, hypertension and hypokalemia. Endocrine investigations were suggestive of ACTH-dependent hypercortisolism, and dynamic testing (overnight dexamethasone suppression test [ODST], and low-dose and high-dose dexamethasone suppression tests [LDDST and HDDST]) was indicative for pituitary ACTH hypersecretion in all cases (- Table $\mathbf{1}$ ).

Random cortisol levels were high in all cases suspecting Cushing's syndrome ( - Table 1). Serum cortisol levels at 8 am after an ODST ( $1 \mathrm{mg}$ once) and LDDST ( $0.5 \mathrm{mg}$ every 6 hours for 2 days) were not adequately suppressed, which confirmed Cushing syndrome (-Table 1). A subsequent HDDST (2 mg every 6 hours for 2 days) to confirm Cushing disease was performed. Serum cortisol was suppressed by more than $50 \%$ compared with baseline, supporting a definite diagnosis of Cushing disease ( $\mathbf{- T a b l e ~} \mathbf{1}$ ).

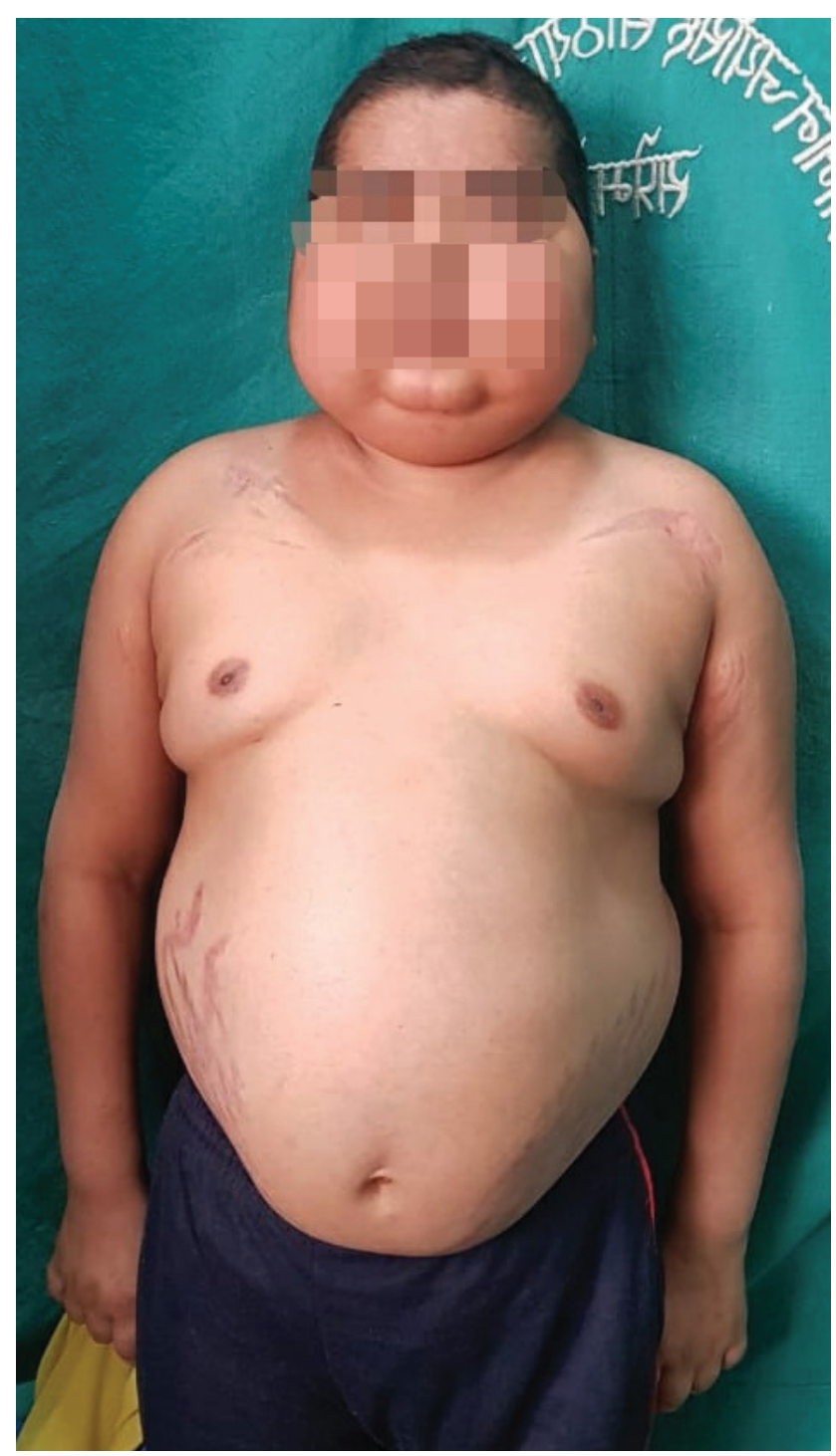

Fig. 1 Photograph of patient.
- Table 2 shows the demographic profile and anthropometric parameters of patients included in the study. All four patients were hypertensive with a normal heart rate.

Previous test results were strongly suggestive of Cushing disease rather than an ectopic ACTH-producing tumor, and a dynamic thin-slice pituitary MRI was performed. The MRI (-Fig. 2) showed a heterogeneous enhancing lesion in the pituitary gland, and pituitary microadenoma was suspected. DEXA scan of hip joint and lumbar spine was suggestive of osteoporosis in all cases.

Transsphenoidal surgery was considered the initial treatment of choice. As preservation of normal pituitary tissue is directly related to surgical success and prognosis, bilateral IPSS (-Fig. 3) was performed by an expert neuroradiologist to determine the localization and laterality of ACTH secretion. The maximum ratio of ACTH concentrations between the inferior petrosal sinus and peripheral vein on the both sides after injection of desmopressin was measured and left/right lateralization of ACTH secretion was suggested (-Tables 3 and 4). Subsequently, gross total resection of the

Table 1 Serum cortisol levels

\begin{tabular}{|l|l|l|l|l|l|}
\hline & Basal & ODST & LDDST & HDDST & $\begin{array}{l}\text { Postoperation } \\
\text { day } 1\end{array}$ \\
\hline Case 1 & 33.50 & 30.0 & 23.09 & 2.95 & 16.36 \\
\hline Case 2 & 37.82 & 33.24 & 27.65 & 3.41 & 27.63 \\
\hline Case 3 & 37.08 & 18.69 & 29.32 & 9.88 & - \\
\hline Case 4 & 46.31 & 22.1 & 11.96 & 14.63 & 11.61 \\
\hline
\end{tabular}

Abbreviations: HDDST, high-dose dexamethasone suppression test; LDDST, low-dose dexamethasone suppression test; ODST, overnight dexamethasone suppression test.

Table 2 Demographic profile and anthropometric parameters

\begin{tabular}{|l|l|l|l|l|}
\hline & Age/Sex & $\begin{array}{l}\text { Height } \\
(\mathbf{c m})\end{array}$ & $\begin{array}{l}\text { Weight } \\
(\mathbf{k g})\end{array}$ & BMI $\left(\mathrm{kg} / \mathrm{m}^{2}\right)$ \\
\hline Case 1 & $34 \mathrm{y} /$ female & 157 & 60 & 24.34 \\
\hline Case 2 & $35 \mathrm{y} /$ male & 153 & 62 & 26.49 \\
\hline Case 3 & $13 \mathrm{y} /$ female & 155 & 65 & 27.06 \\
\hline Case 4 & $10 \mathrm{y} /$ male & 131 & 42 & 24.56 \\
\hline
\end{tabular}

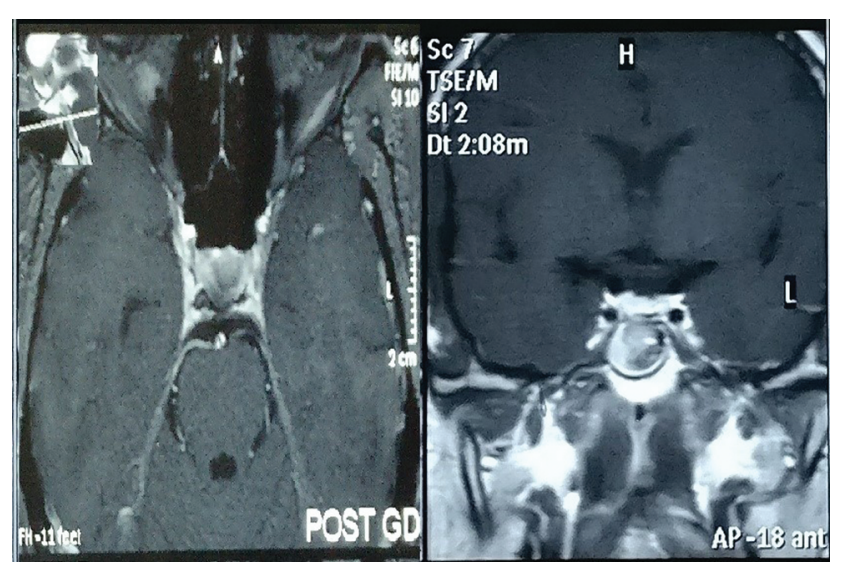

Fig. 2 Dynamic MRI of sella (axial and coronal view). 


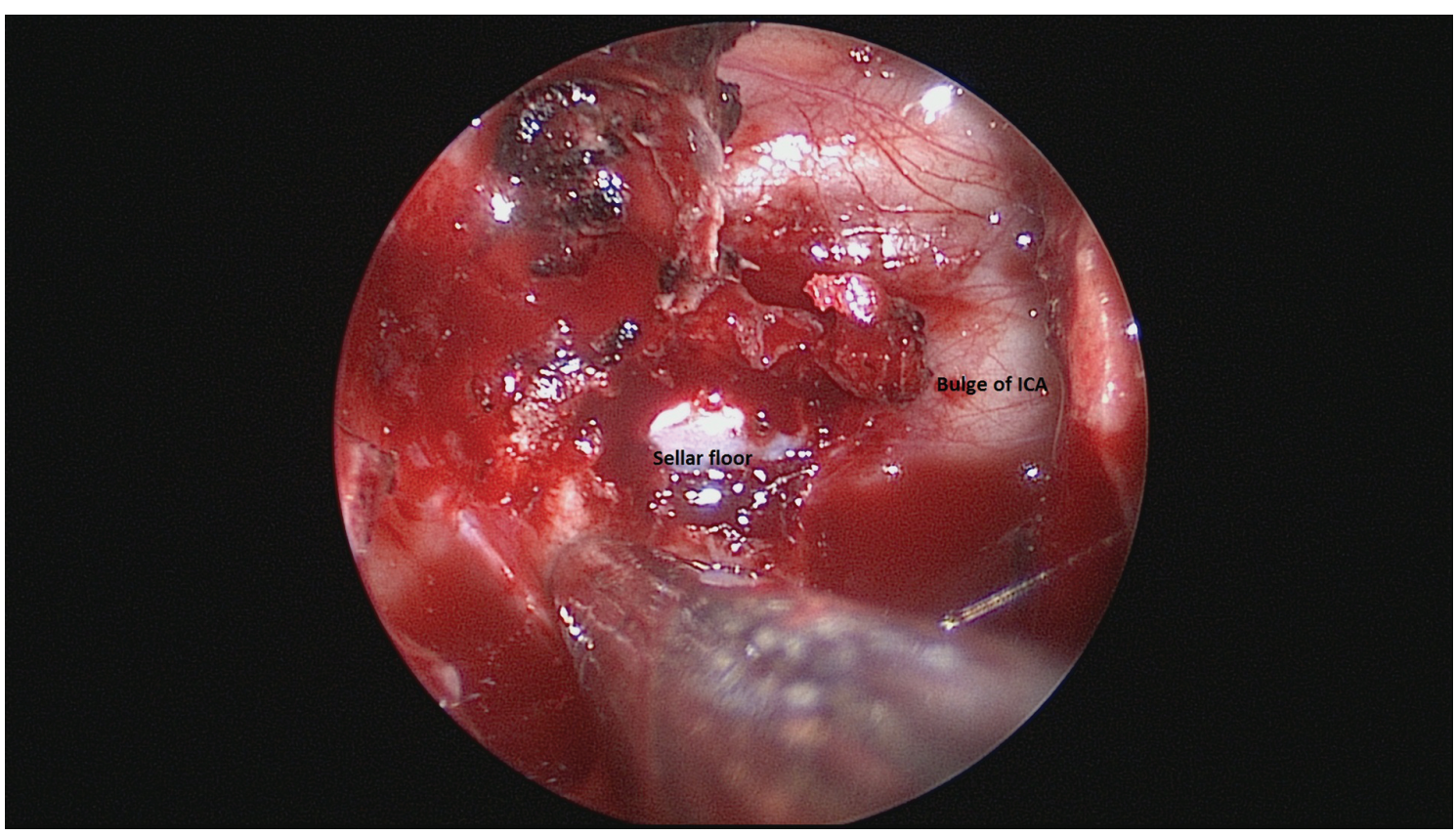

Fig. 3 Intraop photograph showing sellar floor and bilateral ICA bulge. ICA, internal carotid artery.

Table 3 ACTH values basal and post desmopressin stimulation from both petrosal sinuses and femoral

\begin{tabular}{|c|c|c|c|c|c|c|c|c|}
\hline & \multicolumn{8}{|c|}{ Central/peripheral ACTH ratio } \\
\hline & \multicolumn{2}{|c|}{-05 minutes } & \multicolumn{2}{|c|}{ - 01 minute } & \multicolumn{2}{|c|}{+05 minutes } & \multicolumn{2}{|c|}{+10 minute } \\
\hline & Right & Left & Right & Left & Right & Left & Right & Left \\
\hline Case 1 & 4.35 & 11 & 1.89 & 11.25 & 1.69 & $>14.5$ & 1.5 & $>12.65$ \\
\hline Case 2 & 10.13 & 2.19 & 5.37 & 1.14 & 6.31 & 1.29 & 8.63 & 2.17 \\
\hline Case 3 & 3.99 & 0.39 & 4.13 & 0.34 & 3.81 & 0.60 & 0.29 & 0.45 \\
\hline \multirow[t]{3}{*}{ Case 4} & 9.91 & 1.13 & 4.47 & 4.07 & 3.0 & 1.16 & 6.83 & 1.54 \\
\hline & \multicolumn{8}{|c|}{ Inter IPS gradient (left/right) or (right/left) } \\
\hline & \multicolumn{2}{|c|}{ - 05 minutes } & \multicolumn{2}{|c|}{ - 01 minutes } & \multicolumn{2}{|c|}{ + 05 minutes } & \multicolumn{2}{|c|}{+10 minutes } \\
\hline Case 1 & \multicolumn{2}{|l|}{2.54} & \multicolumn{2}{|l|}{5.1} & \multicolumn{2}{|c|}{$>8.56$} & \multicolumn{2}{|l|}{$>8.44$} \\
\hline Case 2 & \multicolumn{2}{|l|}{7.56} & \multicolumn{2}{|l|}{3.34} & \multicolumn{2}{|l|}{5.14} & \multicolumn{2}{|l|}{5.37} \\
\hline Case 3 & \multicolumn{2}{|l|}{10.1} & \multicolumn{2}{|l|}{11.83} & \multicolumn{2}{|l|}{6.26} & \multicolumn{2}{|l|}{2.20} \\
\hline Case 4 & \multicolumn{2}{|l|}{8.86} & \multicolumn{2}{|l|}{1.12} & \multicolumn{2}{|l|}{2.51} & \multicolumn{2}{|l|}{4.43} \\
\hline
\end{tabular}

Table 4 Basal and postdesmopressin stimulation highest central to peripheral ACTH ratio and interpetrosal ACTH gradient

\begin{tabular}{|c|c|c|c|c|c|c|}
\hline & $\begin{array}{l}\text { Highest central/ } \\
\text { peripheral ACTH } \\
\text { ratio } \\
\text { (basal) }\end{array}$ & $\begin{array}{l}\text { Highest central/ } \\
\text { peripheral ACTH } \\
\text { ratio } \\
\text { (poststimulation) }\end{array}$ & $\begin{array}{l}\text { Highest inter } \\
\text { IPS ratio }(L>R) \\
\text { OR }(R>L) \\
\text { (Basal) }\end{array}$ & $\begin{array}{l}\text { Highest inter } \\
\text { IPS ratio } \\
\text { (Poststimulation) } \\
(L>R) \text { OR }(R>L)\end{array}$ & Diagnosis & Lateralization \\
\hline Case 1 & 11 & $>14.5$ & 5.1 & $>8.56$ & $\begin{array}{l}\text { Cushing } \\
\text { disease }\end{array}$ & Left \\
\hline Case 2 & 10.13 & 8.63 & 7.56 & 5.37 & $\begin{array}{l}\text { Cushing } \\
\text { disease }\end{array}$ & Right \\
\hline Case 3 & 4.13 & 3.81 & 11.83 & 6.26 & $\begin{array}{l}\text { Cushing } \\
\text { disease }\end{array}$ & Right \\
\hline Case 4 & 9.91 & 6.83 & 8.86 & 4.43 & $\begin{array}{l}\text { Cushing } \\
\text { disease }\end{array}$ & Right \\
\hline
\end{tabular}




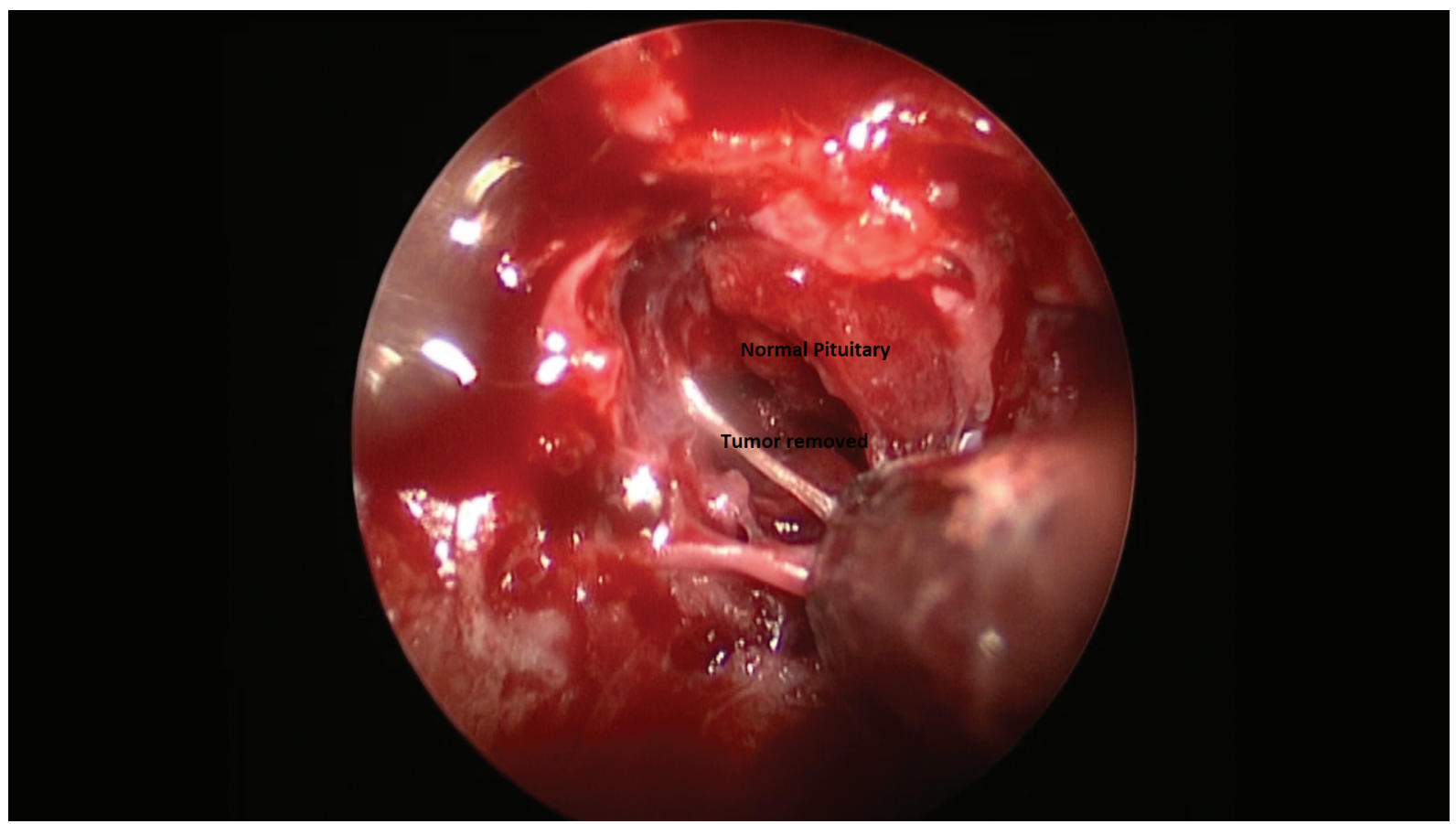

Fig. 4 Intraop photograph after removal of tumor.

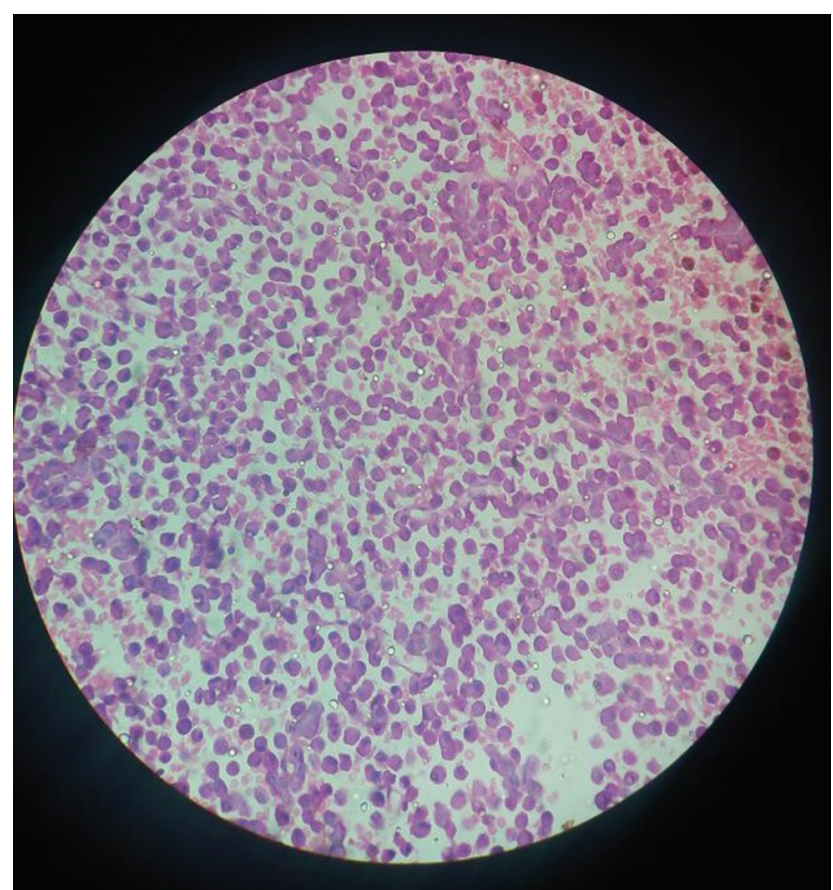

Fig. 5 Histopathology image showing ACTH secreting pituitary adenoma.

tumor by endoscopic endonasal transsphenoidal approach was performed ( - Fig. 4).

Pathology of the biopsied tissue confirmed a pituitary adenoma ( - Fig. 5). Postoperative MRI showed no gross residual tumor, and there were no significant complications. Basal serum cortisol levels measured on the day after surgery were markedly decreased in two patients, while one patient continued to show raised levels of cortisol, which confirmed that the surgery had been successful in two patients ( - Table $\mathbf{1}$ ). One patient with raised levels of cortisol during postoperative period was prescribed Ketoconazole ( $400 \mathrm{mg} /$ day) for 6 months. At 6 months follow-up, patient showed cortisol level as $14.83 \mathrm{Ug} / \mathrm{dl}$. The patient on ketoconazole therapy was closely monitored for liver function tests. One patient refused surgery and was managed with long-term ketoconazole. Remaining patients were prescribed long-term oral hydrocortisone for 6 weeks and were discharged.

\section{Discussion}

Cushing's disease is one of the causes of Cushing's syndrome characterized by increased secretion of ACTH from the anterior pituitary. This is most often due to pituitary adenoma or due to excess production of hypothalamus corticotrophinreleasing hormone. Patients afflicted with Cushing's disease usually present with signs and symptoms secondary to the presence of excess cortisol or ACTH. Classical features include centripetal obesity, moon face, hirsutism, and plethora, but systemic involvement is also seen. ${ }^{1}$ Obesity, hypogonadism, psychiatric abnormality, myopathy, hypertension, and infections are representative clinical manifestations of Cushing syndrome. ${ }^{1}$ Diagnosis is first made by diagnosing Cushing's syndrome, which can be difficult to do clinically, as the most characteristic symptoms only occur in a minority of patients. ${ }^{5}$ Investigation of Cushing syndrome is carried out over two steps. The first is to confirm Cushing syndrome clinically and biochemically by checking the circadian rhythm of plasma cortisol and urinary-free cortisol (UFC) excretion, and then performing an overnight or LDDST. ${ }^{1}$ The next step is to determine the cause of Cushing's syndrome, which includes 
estimation of the levels of plasma ACTH, performing HDDST, IPSS, MRI scanning of the pituitary and adrenal glands, and testing for tumor markers.

IPSS is a more accurate but invasive test used to differentiate pituitary from ectopic or adrenal Cushing's syndrome. ${ }^{6}$ It was first performed in 1977 by Corrigan. ${ }^{7}$ A corticotropin gradient sample via IPSS is required to confirm diagnosis when pituitary MR imaging and biochemical diagnostic tests have been inconclusive. If the central/peripheral ACTH ratio determined by IPSS increases by more than 2 prior to administration of desmopressin, and by more than 3 after administration of desmopressin, then Cushing disease due to microadenoma is strongly suggested.

In our case series, the peak central/peripheral ratio during right and left IPSS suggested right lateralization in three patients and left in one patient (- Table 4). The intraoperative findings showed tumor on the left side in one patient, while tumor on right side is noticed in two patients. So, these findings were concordant with bilateral IPSS results. Therefore, IPSS was thought to be the most reliable test to distinguish between Cushing disease and ectopic ACTH syndrome, particularly in cases where current imaging techniques have limitations. Additionally, IPSS can provide more precise information about the localization of the tumor to the neurosurgeon for successful resection. One patient with failure of surgery was prescribed ketoconazole in doses of $400 \mathrm{mg} /$ day for 6 months. At 6 month follow-up visit, the patient showed decrease in serum cortisol levels. During this period of 6 months, the patient was monitored closely for liver function tests. Ketoconazole is effective for long-term control of hypercortisolism of either pituitary or adrenal origin. Its effect appears to be mediated by inhibition of adrenal 11ß-hydroxylase and 17,20- lyase, and it, in some unknown way, prevents the expected rise in ACTH secretion in patients with Cushing's disease ${ }^{7}$

Studies of the efficacy of desmopressin have mostly yielded positive results. Deipolyi et al performed 20 cases of IPSS using desmopressin, and demonstrated 94.5\% sensitivity, comparable with $\mathrm{CRH}$ stimulation. ${ }^{8}$ Among 36 cases in the literature, IPSS using desmopressin had a sensitivity of $95 \%$ for Cushing disease, and a specificity of $100 \%$ for ectopic ACTH secretion. ${ }^{9}$ We administered demopressin as a stimulant for IPSS, considering the wide availability, sensitivity and specificity of desmopressin compared with $\mathrm{CRH}$.

In our cases, there were no serious complications during IPSS, such as venous thrombosis, pulmonary embolism, cranial nerve palsy, or brainstem vascular damage.

\section{Conclusion}

Careful surgical, neuroradiological, and pathological exploration are necessary not only to correctly identify pituitary microadenomas but also essentially avoid missing the causative adenomas and risking surgical failure. Bilateral inferior petrosal sinus sampling (BIPSS) following $\mathrm{CRH}$ stimulation is the current gold standard technique in the diagnosis of Cushing disease. Indeed, failure to remove the ACTH secreting lesion is the most frequent cause of persistent hypercortisolism. Ketoconazole is a safe and effective drug for long-term control of hypercortisolism of pituitary origin, but has the potential hepatotoxicity that requires careful biochemical monitoring.

\section{Conflict of Interest}

None declared.

\section{References}

1 Melmed S, Polonsky KS, Larsen PR, Kronenberg HM, eds. Williams Textbook of Endocrinology, 12th ed. Philadelphia: Saunders/Elsevier; 2011

2 Savage MO, Chan LF, Grossman AB, Storr HL. Work-up and management of paediatric Cushing's syndrome. Curr Opin Endocrinol Diabetes Obes 2008;15(4):346-351

3 Pecori Giraldi F, Cavallo LM, Tortora F, et al; Altogether to Beat Cushing's Syndrome Group. The role of inferior petrosal sinus sampling in ACTH-dependent Cushing's syndrome: review and joint opinion statement by members of the Italian Society for Endocrinology, Italian Society for Neurosurgery, and Italian Society for Neuroradiology. Neurosurg Focus 2015;38(2):E5

4 Lad SP, Patil CG, Laws ER Jr, Katznelson L. The role of inferior petrosal sinus sampling in the diagnostic localization of Cushing's disease. Neurosurg Focus 2007;23(3):E2

5 Nieman LK, Ilias I. Evaluation and treatment of Cushing's syndrome. Am J Med 2005;118(12):1340-1346

6 Deipolyi A, Karaosmanoğlu A, Habito C, et al. The role of bilateral inferior petrosal sinus sampling in the diagnostic evaluation of Cushing syndrome. Diagn Interv Radiol 2012;18(1):132-138

7 Loli P, Berselli ME, Tagliaferri M. Use of ketoconazole in the treatment of Cushing's syndrome. J Clin Endocrinol Metab 1986;63(6):1365-1371

8 Deipolyi AR, Alexander B, Rho J, Hirsch JA, Oklu R. Bilateral inferior petrosal sinus sampling using desmopressin or corticotropic-releasing hormone: a single-center experience. J Neurointerv Surg 2015;7(9):690-693

9 Castinetti F, Morange I, Dufour H, et al. Desmopressin test during petrosal sinus sampling: a valuable tool to discriminate pituitary or ectopic ACTH-dependent Cushing's syndrome. Eur J Endocrinol 2007;157(3):271-277 